\title{
Surface Modification of Cyclic Olefin Copolymers for Osteochondral Defect Repair Can Increase Pro-Destructive Potential of Human Chondrocytes In Vitro
}

\author{
M. POLANSKÁ ${ }^{1}$, H. HULEJOVÁ ${ }^{1}$, M. PETRTÝ ${ }^{2}$, Z. BASTL ${ }^{3}$, I. SPIROVOVÁ ${ }^{3}$, \\ Z. KRULIŠ ${ }^{4}$, Z. HORÁK ${ }^{4}$, D. VEIGL ${ }^{5}$, L. ŠENOLT ${ }^{1}$
}

${ }^{1}$ Institute of Rheumatology, First Medical Faculty, Charles University Prague, Prague, Czech Republic, ${ }^{2}$ Czech Technical University, Faculty of Civil Engineering, Prague, Czech Republic, ${ }^{3}$ Institute of Physical Chemistry, Academy of Sciences, Prague, Czech Republic, ${ }^{4}$ Institute of Macromolecular Chemistry, Academy of Sciences, Prague, Czech Republic, ${ }^{5}$ First Orthopedic Clinic First Faculty of Medicine and Faculty Hospital Motol, Prague, Czech Republic

Received December 16, 2008

Accepted February 12, 2009

On-line June 19, 2009

\section{Summary}

Materials on the basis of cycloolefin copolymers (COC) are suitable for subchondral defect repairs. The objective of this study was to evaluate the influence of surface modification of COC and COC/LLDPE blends on the viability and gene expression of chondrocytes. Human chondrocytes were incubated on the surface of the studied materials. Half of the materials were plasmatically modified with a subsequent type II collagen application. The gene expression of matrix metalloproteinases (MMP-1,-3,-13), pro-inflammatory cytokines (IL-1, TNF-alpha) and apoptotic molecules (BAX, Bcl-2) was evaluated using quantitative Taq-Man PCR after $48 \mathrm{~h}$ incubation. Chondrocyte viability was evaluated by the MTT test after 2,4 and 8 days of incubation. The synthesis of MMPs was measured by ELISA assay in cell culture medium after $48 \mathrm{~h}$ of incubation. Chondrocytes incubated on plasmatically modified in contrast to unmodified materials demonstrated significantly increased gene expression of IL-1 ( $p<0.05)$, MMP-1 and MMP-3 ( $p<0.05$ for both comparisons) as well as MMP-13 $(p<0.001)$. Increased gene expression was confirmed by significantly increased production of active forms of particular MMPs into the cell culture medium. Unlike surface unmodified polymers, the modified materials showed timedependent reduction of chondrocyte viability. The gene expression of TNF-a and apoptotic molecules by chondrocytes was not significantly changed by different materials. Cycloolefin copolymers and their blends may represent suitable materials for tissue engineering, however, their surface modification followed by collagen type II application may, at least under in vitro conditions, reduce the viability of chondrocytes and induce their pro-destructive behavior. The potential benefit or disadvantage of surface modifications of materials for osteochondral defect repairs needs to be further elucidated.

\section{Key words}

Osteochondral defects • Cycloolefin copolymer • Chondrocytes • Biocompatibility

\section{Corresponding author}

M. Polanská, Institute of Rheumatology, Na Slupi 4, 12850 Prague 2, Czech Republic. E-mail: polanska@revma.cz

\section{Introduction}

Osteoarthritis (OA) is one of the most frequent joint impairment with the underlying hyaline cartilage defect, gradual loss of proteoglycans and altered collagen structure (Goldring and Goldring 2007). The precondition for the development of these changes is a limited repair capacity of the extracellular matrix of hyaline cartilage. Mechanical forces play a major role in the development of OA. Age also represents an important risk factor. Nevertheless, osteochondral defects, which represent the predispositions to mechanical instability of the joint and subsequent development of the degenerative arthritic 
process, may also occur in the young age following a joint trauma (Kraan et al. 2002). Chondrocytes as well as subchondral bone are actively involved in the pathogenesis of $\mathrm{OA}$ by producing proinflammatory cytokines in an increased amount, e.g. tumor-necrosis factor)-alpha (TNF- $\alpha$ ), interleukins IL-1 and IL-6 or prostaglandins, nitric oxide (NO) and matrix metalloproteinases (MMPs) (Hedbom et al. 2002, Hulejová et al. 2007). Increased apoptosis of chondrocytes is expected to be significantly involved in the pathogenesis of advanced OA (Carlo and Loeser 2008).

Severe joint impairment by the osteoarthritic process or major cartilage defects often requires a total joint replacement. The matter of debate are smaller but symptomatic chondral and osteochondral defects that may be potentially treated by using methods of tissueengineering, implantation of autologous chondrocytes, transplantation of osteochondral autografts, or an artificial osteochondral defect repair (Chajra et al. 2008). The purpose of such procedures is to reduce pain, induce regeneration of the affected articular cartilage and prevent the progression of OA. The research of biological materials for artificial replacement of skeletal elements is focused upon those materials whose biomechanical properties are as similar as possible to organic tissues and which are tolerated by the biological environment.

Out of all materials, synthetic polymers have a special position and are well tolerated by the biological environment (Martin et al. 2007). Biocompatibility of polymers in implants depends on the interactions occurring between their surface and a biological environment. The first step of interaction of living body with a surface is protein adsorption. This interaction can be strongly influenced by modifying the surface chemistry, the surface charge and topography. Because of the inert nature of polymer surfaces they usually need to be functionalized. It was already reported that plasma treatment could modulate chondrocyte gene expression (Tsai et al. 2005). Collagen adsorption is known to promote cell adhesion and proliferation. For the purposes of this study, the authors selected cyclic olefin copolymers that were demonstrated to be suitable for subchondral defect repairs. Surface modification by plasma and subsequent collagen application generally increases perspectives for the material application (Pešáková et al. 2005). In this paper, we evaluated the impact of surface modification of biological implants for osteochondral defect repair with plasma and subsequent collagen type II application on the viability and gene expression of human chondrocytes.

\section{Materials and Methods}

\section{Basic components}

COC - cycloolefin copolymer, chemically copolymer ethylene-norbornen (60-40), commercial product Topas 8007F- 400, Topas Advanced Polymers (Germany).

LLDPE - linear low density polyethylene, commercial product Exact 0102, Exxon, (USA)

Polymeric materials used for in vitro experiments:

\section{a) $\mathrm{COC}$}

b) $\mathrm{COC}$ with surface plasmatic modification $(\mathrm{N}, \mathrm{O})$ and application of $0.3 \%$ type II collagen

c) COC/LLDPE (80/20) blend

d) COC/LLDPE (80/20) blend with surface plasmatic modification $(\mathrm{N}, \mathrm{O})$ and application of $0.3 \%$ type II collagen

$\mathrm{COC}$ and its blend were processed by mixing of components in the W $50 \mathrm{EH}$ chamber of a Brabender Plasticorder at $190{ }^{\circ} \mathrm{C}$ and $60 \mathrm{rpm}$ for $8 \mathrm{~min}$. All components were dosed into the mixer chamber together at the beginning of mixing. The molten material was taken out and pressed into plates from which the test samples were prepared. COC/LLDPE blend was irradiated by $\gamma$-rays (radiation dose $50 \mathrm{kGy}$ ) to obtain crosslinked structure in LLDPE particles dispersed in COC matrix.

One half of both the samples were modified by the nitrogen MW plasma using MW reactor equipped with SLAN I OV 425 magnetron (Plasma Consult) with power of $300 \mathrm{~W}$, pressure of nitrogen $80 \mathrm{~Pa}$, nitrogen flow $15 \mathrm{scm}^{3} / \mathrm{min}$ and exposure $15 \mathrm{~min}$. It was deduced from photoelectron spectra that this treatment resulted in production of hydroxyl, carbonyl, carboxyl and ammine functional groups on the polymer surface. Before use, the samples were sterilized with ethylene oxide. Materials with plasmatically modified surface were sterile coated with type II collagen using $0.3 \%$ solution in PBS buffer and $2 \mathrm{~h}$ incubation at room temperature. Collagen type II was prepared as described previously (Pešáková et al. 1994).

\section{Cell cultures}

For in vitro experiments, two different cell lines of commercially available human chondrocytes (Normal 

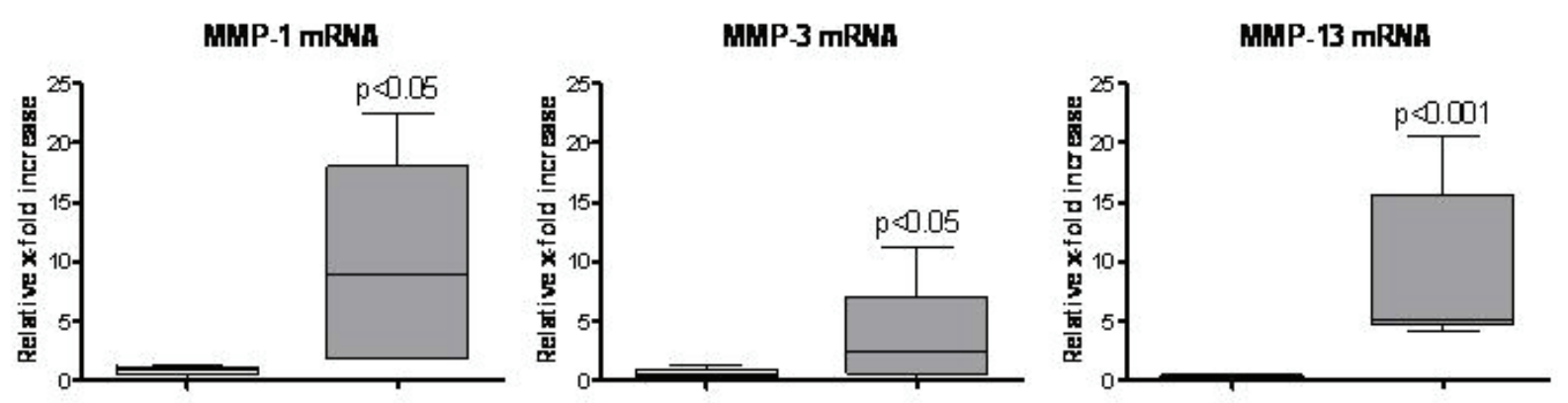

Fig. 1. Increased gene expression of several matrix degrading enzymes (MMPs) by human chondrocytes after 48-h incubation with modified in contrast to unmodified polymeric materials. Relative gene expression is corrected to the gene expression of control human chondrocytes incubated without these materials. White boxes represent unmodified materials, gray boxes represent modified materials.

Table 1. Increased levels of active MMPs secreted by chondrocytes to the cell culture supernatants after 48-h incubation with modified in contrast to unmodified polymeric materials.

\begin{tabular}{lccc}
\hline & $\begin{array}{c}\text { Materials } \\
\text { without } \\
\text { surface } \\
\text { plasmatic } \\
\text { modification }\end{array}$ & $\begin{array}{c}\text { Materials with } \\
\text { surface } \\
\text { plasmatic } \\
\text { modification }\end{array}$ & p \\
& & \\
\hline$M P-1$ & $120.15 \pm 83.64$ & $237.22 \pm 135.43$ & $<0.05$ \\
$M M P-3$ & $15.50 \pm 9.95$ & $41.27 \pm 12.80$ & $<0.001$ \\
$M M P-13$ & $2.32 \pm 1.65$ & $24.61 \pm 10.07$ & $<0.001$ \\
\hline
\end{tabular}

Human Articular Chondrocytes, Knee cryopreserved NHAC-kn13354 and NHAC-kn14757, DIAGENES, Czech Republic) were used. Chondrocytes were incubated in a specific differentiation medium (Chondrocyte Differentiation Medium CDM BulletKit, DIAGENES, Czech Republic) containing $5 \%$ FCS under $37{ }^{\circ} \mathrm{C}$ in the atmosphere with $5 \%$ of $\mathrm{CO}_{2}$. The fifth passage was used for the experiments. The testing of materials was conducted in 12-well plates with the materials of $21 \mathrm{~mm}$ diameter inserted at the very bottom of each well.

\section{Gene expression}

Chondrocyte cell lines were seeded in the amount of $10^{5}$ cells per well and incubated for the period of $48 \mathrm{~h}$ on individual materials, which were placed at the bottom of the relevant wells. All experiments were carried out in triplets. The negative control related to modified materials was represented by the same number of chondrocytes incubated in the absence of materials.
Following the time interval, cells were lysed using RLT Lysis Buffer (Qiagen). The total RNA was isolated from the cell lysate and by reverse transcription was transferred to complementary (c)DNA, which was used as the quantitative Taq-Man PCR reaction template. Gene expression of matrix metalloproteinases (MMP-1, MMP-3 and MMP-13), proinflammatory cytokines (IL-1, TNF- $\alpha$ ) and apoptotic molecules (BAX, Bcl-2) (Sigma, Czech Republic) was evaluated. A probe for $18 \mathrm{~S}$ (Applied Biosystems) was used as the endogenous control.

Evidence of cell viability and cytotoxicity of tested materials using MTT test

Cell viability was carried out by the MTT test (Sigma, Czech Republic). MTT is a colorimetric method, the distinction between viable and dead cells is based on the ability of viable cells to reduce yellow, soluble MTT tetrazolium salt (3-4,5-dimethylazol-2-yl)-2,5-diphenyl tetrazolium) by the mitochondrial enzyme succinate dehydrogenase to insoluble blue formasan. Formasan is then dissolved by dimethyl sulfoxide, or by another organic solvent, if applicable. The absorbance of the color product is measured by photometry at $570 \mathrm{~nm}$ (ELISA reader SUNRISE). One chondrocyte cell line was incubated on tested materials for the period of 2,4 and 8 days. After the particular intervals, MTT staining was carried out in one experiment to check for cell viability.

\section{ELISA}

Using the ELISA assay, levels of active MMP-1, MMP-3 and MMP-13 (Ray Biotech, Inc., Norcross GA) were established in cell culture supernatant after 48 hours of incubation as described previously (Šenolt et al. 2006). The analysis was performed using ELISA reader 

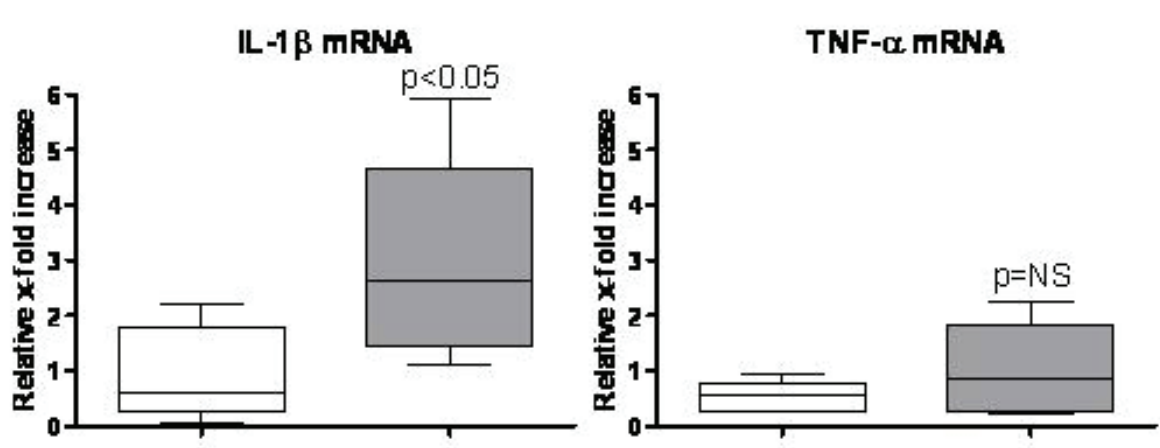

BAX mRNA
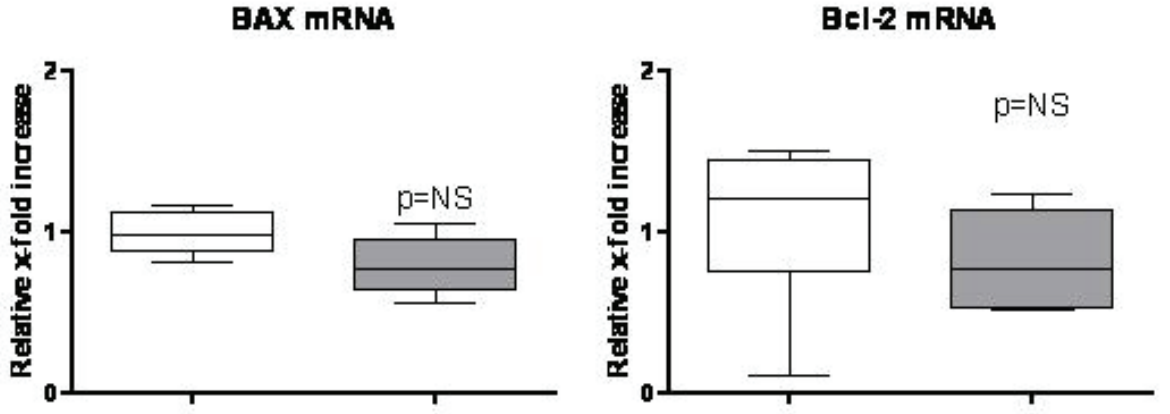

Fig. 2. Gene expression of proinflammatory cytokines IL-1 and TNF-a by human chondrocytes after 48-h incubation with modified and unmodified polymeric materials. Relative gene expression is corrected to the gene expression of control human chondrocytes incubated without these materials. White boxes represent unmodified materials, gray boxes represent modified materials.

Fig. 3. Gene expression of apoptotic molecules $\mathrm{Bcl}-2$ and $\mathrm{BAX}$ by human chondrocytes after 48-h incubation with modified and unmodified polymeric materials. Relative gene expression is corrected to the gene expression of control human chondrocytes incubated without polymeric materials. White boxes represent unmodified materials, gray boxes represent modified materials.
SUNRISE (Tecan, Salzburg, Austria) at the wavelength of $450 \mathrm{~nm}$. The measured absorbance was related to the number of cells in the particular experiment. Testing was carried out in two independent experiments.

\section{Statistical analysis}

The statistical analysis was performed on GraphPad Prism 4 software. Paired t-test was used for comparison between two groups as appropriate. $\mathrm{P}<0.05$ value was considered statistically significant.

\section{Results}

Surface modification of materials induces matrix metalloproteinases expression

Figure 1 shows modulated gene expression of individual MMPs by human chondrocytes after 48-h incubation with individual polymeric materials corrected to the gene expression of chondrocytes incubated without these materials. Plasmatic modification in contrast to unmodified materials significantly induced expression of MMP-1 and MMP-3 (fold increase: 8.14 vs. 0.78 and 3.77 vs. 0.55 , respectively; $\mathrm{p}<0.05$ for both comparisons) as well as MMP-13 (fold increase: 7.77 vs. 0.26; $\mathrm{p}<0.001$ ). On the contrary, unmodified materials lead to reduced expression of particular MMPs by chondrocytes (Fig. 1). Increased gene expression of the MMPs was confirmed by measuring their active forms secreted by chondrocytes to the cell culture supernatants (Table 1).
Modified polymers in contrast to unmodified materials significantly induced production of MMP-1 $(\mathrm{p}<0.05)$, MMP-3 and MMP-13 ( $<0.001$ for both comparisons).

Proinflammatory cytokines and apoptotic molecules upon surface modification

Incubation of human chondrocytes with plasmatically modified compared to unmodified materials significantly increased expression of IL-1 mRNA (fold increase: 2.48 vs. $0.92 ; \mathrm{p}<0.05$ ) after $48 \mathrm{~h}$ (Fig. $2 \mathrm{a}$ ). The expression of TNF- $\alpha$ mRNA was not significantly changed upon the presence of tested materials (Fig. 2b). The gene expression of apoptotic molecules BAX and Bcl2 was also not significantly changed upon incubation of chondrocytes with plasmatically modified or unmodified materials (Fig. 3).

\section{Chondrocyte viability upon surface modification}

Cell viability and cytotoxicity of COC materials examined by the MTT test on Day 2, 4 and 8 is illustrated in Figure 4. The viability/proliferation of chondrocytes on materials without plasmatic modification was gradually increasing. From Day 4 on, however, there were apparently less viable chondrocytes growing on the COC and COC blend modified materials compared to materials without modified surfaces. The greatest difference in chondrocyte viability was observed between modified and unmodified COC and COC blend materials on Day 8. 


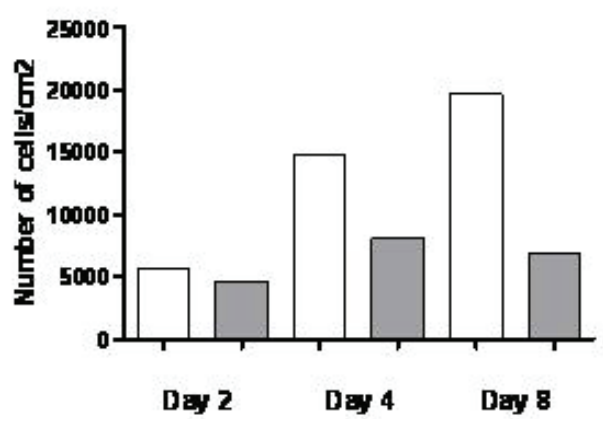

Fig. 4. Plasmatic modification of materials reduced chondrocyte viability/proliferation as evaluated by MTT colorimetric method. White columns represent unmodified materials, gray columns represent modified materials.

\section{Discussion}

In the present study we examined the effect of modified and unmodified polymeric materials for osteochondral defect repair on human chondrocytes. We demonstrated that under in vitro conditions the modified in contrast to unmodified surface of polymers increased expression of IL-1, induced production of several matrix metalloproteinases and reduced viability of human chondrocytes that may altogether potentially harm the cartilage homeostasis.

Due to limited repair capacity of the articular cartilage, most osteochondral defects caused by traumas are burdening adult and pediatric traumatology as well as orthopedic surgery. Pivotal research into the treatment of osteochondral defects shifts towards the search for a suitable material or "scaffold" with eligible biological properties (Zwingmann et al. 2007). Currently, several different materials are known such as metals, ceramics or organic polymers being used also for joint prosthesis. In the current study, the authors selected cyclic-olefin based polymers (COC and $\mathrm{COC}$ blend) for in vitro experiments. These materials allow active control of the properties such as the modulus of elasticity and tensile strength being suitable for medical application (Ramakrishna et al. 2001). Besides the physico-chemical parameters for the particular material, biocompatibility represents one of the greatest concerns. Toxic substances may cause impaired metabolic activity, reduced cell proliferation or viability, early chondrocyte apoptosis or an increased production of stress proteins and cytokines (Cornelis et al. 1991, Tanzi et al. 1992). Cell proliferation and viability, one of the key parameters for the determination of cytotoxicity of studied materials, are being often determined by MTT test (Shaw 1994, Willumeit et al. 2007). In the current study, we have not observed significant differences between the expressions of apoptotic molecules by chondrocytes exposed to modified or unmodified materials. However, using MTT test, we could demonstrate time-dependent decrease of viability/ proliferation of human chondrocytes being exposed to modified polymers compared to unmodified polymers. Contrary, unmodified materials seem to be well tolerated. This finding is consistent with the observation that higher amounts of hydrophilic groups on polymer chains may reduce adhesion, proliferation and viability of chondrocytes (Pérez Olmedilla et al. 2006).

Furthermore, we demonstrated that the modified in contrast to unmodified materials could induce expression of proinflammatory cytokine IL-1 by human chondrocytes. Consistently with the evidence of IL-1 being a key regulator of articular cartilage degradation (Hedbom et al. 2002), we found an increased production of several MMPs by chondrocytes exposed to modified, but not to unmodified materials. Since collagen fragments were described to upregulate production of some MMPs, mostly MMP-13 (Sunk et al. 2007, Tchetina et al. 2007), it can be speculated that increased expression of MMPs can be the consequence of collagen application to modified surface of materials. Thereby, based on these data, one could not support the idea of benefits for plasmatic modification and subsequent collagen application of osteochondral defect implants. On the contrary, it has been demonstrated that type II collagenbased matrices contribute to the invasion of cells that are directed into a chondrocyte phenotype and may be the choice for cartilage regeneration of the superficial layer (Buma et al. 2003). In addition, our data cannot yield final assessment for the in vivo condition, as our preliminary results show a similar biological tolerance of both modified and unmodified polymers implanted into the artificially created osteochondral defects of porcine femoral condyles (unpublished observations). Accordingly, recent work has indicated a similar proliferation and expression of type I, II and X collagens, including catalytic enzymes by bovine chondrocytes where modified collagen-based scaffolds were concerned (Chajra et al. 2008). Thereby, it seems that positive results of surface modification prevail over the negative results. However, further studies should confirm benefits or disadvantages of surface material modification used for osteochondral defect repairs.

In conclusion, cyclic olefin copolymers may represent suitable materials for tissue engineering; 
however, the results of this study suggest that, at least in vitro, plasmatic modification with subsequent collagen application may have an adverse effect on hyaline cartilage repair. More data should be brought by further experiments and in vivo studies of osteochondral defect implants.

\section{Conflict of Interest}

There is no conflict of interest.

\section{Acknowledgements}

The presented work was carried out with the support of a grant provided by Grant Agency of the Czech Republic, reg. no. 106/06/0761.

\section{References}

BUMA P, PIEPER JS, VAN TIENEN T, VAN SUSANTE JL, VAN DER KRAAN PM, VEERKAMP JH, VAN DEN BERG WB, VETH RP, VAN KUPPEVELT TH: Cross-linked type I and type II collagenous matrices for the repair of full-thickness articular cartilage defects--a study in rabbits. Biomaterials 24: 3255-3263, 2003.

CORNELIS M, DUPONT C, WEPIERRE J: In vitro cytotoxicity tests on cultured human skin fibroblasts to predict the toxic potential of surfactants. ATLA 19: 324-337, 1991.

DEL CARLO MJR, LOESER RF: Cell death in osteoarthritis. Curr Rheumatol Rep 10: 37-42, 2008.

GOLDRING MB, GOLDRING SR: Osteoarthritis. J Cell Physiol 213: 626-634, 2007.

HEDBOM E, HÄUSELMANN HJ: Molecular aspects of pathogenesis in osteoarthritis: the role of inflammation. Cell Mol Life Sci 59: 45-53, 2002.

HULEJOVÁ H, BAREŠOVÁ V, KLÉZL Z, POLANSKÁ M, ADAM M, ŠENOLT L: Increased level of cytokines and matrix metalloproteinases in osteoarthritic subchondral bone. Cytokine 38: 151-156, 2007.

CHAJRA H, ROUSSEAU CF, CORTIAL D, RONZIÈRE MC, HERBAGE D, MALLEIN-GERIN F, FREYRIA AM: Collagen-based biomaterials and cartilage engineering. Application to osteochondral defects. Biomed Mater Eng 18: 33-45, 2008.

MARTIN I, MIOT S, BARBERO A, JAKOB M, WENDT D: Osteochondral tissue engineering. J Biomech 40: 750 $765,2007$.

PÉREZ OLMEDILLA M, GARCIA-GIRALT N, PRADAS MM: Response of human chondrocytes to a non-uniform distribution of hydrophilic domains on poly (ethyl acrylate-co-hydroxyethyl methacrylate) copolymers. Biomaterials 27: 1003-1012, 2006.

PEŠÁKOVÁ V, KUBIES D, HULEJOVÁ H, HIMMLOVÁ L: The influence of implant surface properties on cell adhesion and proliferation. J Mater Sci Mater Med 18: 465-473, 2005.

PEŠÁKOVÁ V, ŠTOL M, GILLERY P, MAQUART FX, BOREL JP, ADAM M: The effect of different collagens and proteoglycan on the retraction of collagen lattice. Biomed \& Pharmacother 48: 261-266, 1994.

RAMAKRISHNA S, MAYER J, WINTERMANTEL E, LEONG KW: Biomedical applications of polymer-composite materials: a review. Composites Sci Technol 61: 1189-1224, 2001.

SENOLT L, GRIGORIAN M, LUKANIDIN E, SIMMEN B, MICHEL BA, PAVELKA K, GAY RE, GAY S, NEIDHART M. S100A4 is expressed at site of invasion in rheumatoid arthritis synovium and modulates production of matrix metalloproteinases. Ann Rheum Dis 65: 1645-1648, 2006.

SHAW AJ: Defining cell viability and cytotoxicity. ATLA 22: 124-126, 1994.

SUNK IG, BOBACZ K, HOFSTAETTER JG, AMOYO L, SOLEIMAN A, SMOLEN J, XU L, LI Y: Increased expression of discoidin domain receptor 2 is linked to the degree of cartilage damage in human knee joints: a potential role in osteoarthritis pathogenesis. Arthritis Rheum 56: 3685-3692, 2007.

TANZI MC, VERDEIRO P, LAMPUGNANI MG, RESNATI M, DEJANA E, STURANI E: Cytotoxicity of some catalysts commonlyused in the synthesis of copolymers for biomedical use. J Mater Sci Mater Med 10: 9-12, 1992.

TCHETINA EV, KOBAYASHI M, YASUDA T, MEIJERS T, PIDOUX I, POOLE AR: Chondrocyte hypertrophy can be induced by a cryptic sequence of type II collagen and is accompanied by the induction of MMP-13 and collagenase activity: implications for development and arthritis. Matrix Biol 26: 247-258, 2007. 
TSAI W-B, WEI T-C, LIN M-C, WANG J-Y, CHEN C-H: The effect of radio-frequency discharge treatment of polystyrene on the behavior of porcine chondrocytes in vitro. J Biomater Sci Polymer Ed 16: 699-714, 2005.

VAN DER KRAAN PM, BUMA P, VAN KUPPEVELT T, VAN DEN BERG, WB: Interaction of chondrocytes, extracellular matrix and growth factors: relevance for articular cartilage tissue engineering. Osteoarthritis Cartilage10: 631-637, 2002.

WILLUMEIT R, SCHOSSIG M, CLEMENS H, FEYERABEND F: In-vitro interactions of human chondrocytes and mesenchymal stem cells, and of mouse macrophages with phospholipid-covered metallic implant materials. Eur Cell Mater 13: 11-25, 2007.

ZWINGMANN J, MEHLHORN AT, SÜDKAMP N, STARK B, DAUNER M, SCHMAL H: Chondrogenic differentiation of human articular chondrocytes differs in biodegradable PGA/PLA scaffolds. Tissue Eng 13: 2335-2343, 2007. 